Polymer Journal, Vol. 39, No. 5, pp. 471-477 (2007)

(C) 2007 The Society of Polymer Science, Japan

\title{
Syntheses of Poly[(tetraphenyl-p-silphenylenesiloxane)- co-(tetramethyl-p-silphenylenesiloxane)]s and the Physical Properties of Their Films
}

\author{
Hitoshi Ito, ${ }^{1, \dagger}$ Eiichi AkiYAma, ${ }^{2}$ Yu NAGASE,${ }^{3}$ and Saburo FukUI ${ }^{3}$ \\ ${ }^{1}$ Applied Chemistry Lab., Ebara Research Co., Ltd, 4-2-1 Honfujisawa, Fujisawa 251-8502, Japan \\ ${ }^{2}$ Sagami Chemical Research Center, 2743-1, Hayakawa, Ayase 252-1193, Japan \\ ${ }^{3}$ Department of Applied Chemistry, School of Engineering, Tokai University, \\ 1117 Kitakaname, Hiratsuka 259-1292, Japan
}

(Received December 5, 2006; Accepted February 26, 2007; Published April 9, 2007)

\begin{abstract}
In order to obtain a polysilarylenesiloxane having a high glass transition temperature $\left(T_{\mathrm{g}}\right)$, a high thermal degradation temperature $\left(T_{\mathrm{d}}\right)$, and a good solubility in common solvents to prepare a film, the copolycondensation of 1,4-bis(hydroxydiphenylsilyl)benzene with 1,4-bis(hydroxydimethylsilyl)benzene was studied. Their thermal properties were studied by using a differential scanning calorimetry and a thermogravimetry analysis. The physical properties of copolymer films were also investigated. All the copolymers exhibited the $T_{\mathrm{g}}$ 's, and those increased with the increase of the molar ratio of the units based on 1,4-bis(hydroxydiphenylsilyl)benzene (PS units). The $T_{\mathrm{g}}$ of one of the copolymers, $\mathbf{C P}$-a, reached to $127^{\circ} \mathbf{C}$. CP-c having a relatively high molecular weight showed the highest thermal stability in air, whose $T_{\mathrm{d} 5}$ was $524^{\circ} \mathrm{C}$. Tough self-standing films were obtained from the copolymers by the casting method. These films had much lower gas permeability coefficients than that of polydimethylsiloxanes and low surface energy similarly to the silicon-containing polymers having a phenylene moiety. The gas permeability coefficients of the films decreased, and the densities and the tensile strength of films increased with the increase of the molar ratio of PS units. These results indicated that dense and tough films were obtained from these copolymers.

[doi:10.1295/polymj.PJ2006185]

KEY WORDS Polysilarylenesiloxane / Thermal Degradation Temperature / Copolymerization / Glass Transition Temperature / Gas Permeability /
\end{abstract}

Polysilarylenesiloxanes ${ }^{1,2}$ and their copolymers ${ }^{2-19}$ have been studied as high temperature elastomers whose degradation temperature $\left(T_{\mathrm{d}}\right)$ was greatly higher than that of polydimethylsiloxane (PDMS). Poly(tetramethyl- $p$-silphenylenesiloxane) (polyMS) of a typical polysilarylenesiloxane was synthesized by Merker et al. ${ }^{5}$ and their thermal properties were investigated. According to the literature, ${ }^{3-5}$ polyMS shows a glass transition temperature $\left(T_{\mathrm{g}}\right)$ of $-20^{\circ} \mathrm{C}$, a melting point $\left(T_{\mathrm{m}}\right)$ of $135^{\circ} \mathrm{C}$ and a thermal degradation temperature $\left(T_{\mathrm{d}}\right)$ of $370-390^{\circ} \mathrm{C}$ under helium flow. PolyMS/PDMS and polyMS/PDMS derivatives were synthesized and their thermal and physical properties were also reported. ${ }^{2-19}$

The common characteristics of these polyMS-containing polymers are their high $T_{\mathrm{d}}$ and the low $T_{\mathrm{g}}$, which resulted from their flexible tetramethyldisiloxane units in the main chain. The mechanical strength of these polymers is not enough at high temperature to use as the heat-resistant materials such as a high-temperature coating and a low dielectric insulation material in semiconductor devices. Recently, Kawakami et al., ${ }^{20-22}$ reported the polymer derived from cardo-type 9,9'-bis[4-(dimethylsilyl)phenyl]- fluorene using a new method of the catalytic crossdehydrocoupling polymerization, and that this polymer exhibited high $T_{\mathrm{g}}$ of $160^{\circ} \mathrm{C},{ }^{22}$ however, the physical properties were not reported. We reported that the fully aromatic polysilarylenesiloxanes, poly(tetraphenyl- $p$-silphenylenesiloxane) (polyPS) and poly(tetraphenyl- $p, p^{\prime}$-silbiphenylenesiloxane) (polyBS), showed no weight loss in air below $500^{\circ} \mathrm{C}$ and had high melting temperatures of $323^{\circ} \mathrm{C}$ and $391{ }^{\circ} \mathrm{C}$, respectively. ${ }^{23}$ Unfortunately, these polymers were obtained as insoluble powder, and could not be formed as a thin-film or a self-standing film. Therefore, the physical properties could not be investigated.

On the contrary, polyMS are soluble in common solvents such as chloroform, tetrahydrofuran and toluene, and can be formed as a tough self-standing film. ${ }^{24}$ However, a copolycondensation of a bis(hydroxydiphenylsilyl)arylene and a bis(hydroxydimethylsilyl)arylene have never been studied.

In this paper, the syntheses of the copolymers, poly[(tetraphenyl- $p$-silphenylenesiloxane)-co-(tetramethyl$p$-silphenylenesiloxane)]s, (CP series) were investigated (Scheme). The chemical and the physical structure were studied by the ${ }^{29} \mathrm{Si}$ NMR spectra and X-ray

${ }^{\dagger}$ To whom correspondence should be addressed (Tel: +81-466-83-7022, Fax: +81-466-81-7220, E-mail: itoh.hitoshi@er.ebara.com). 
H. Iто et al.

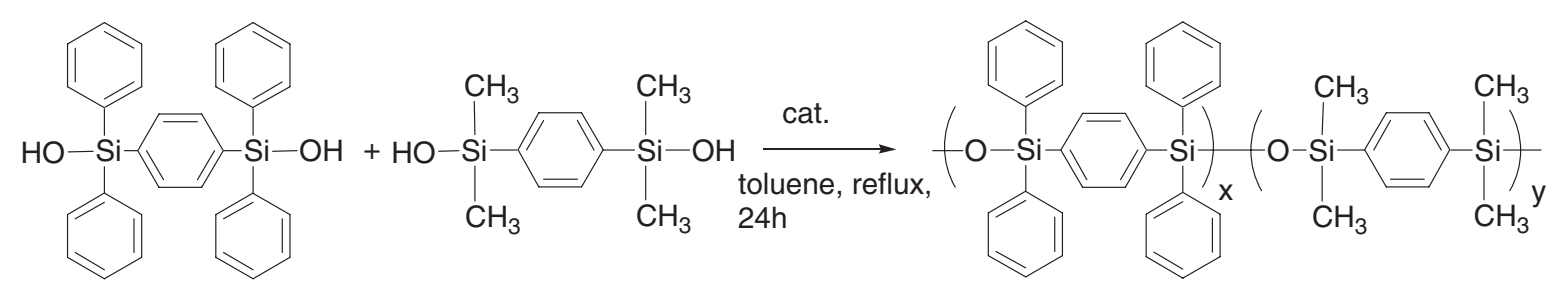

Scheme 1. Synthesis of copolymers.

diffraction (XRD) patterns. The thermal properties of the copolymers were investigated in detail by using a thermogravimetry analysis (TGA) and a differential scanning calorimetry (DSC). The physical properties of the copolymer films, that is, gas permeability, density, surface energy and mechanical strength were also investigated. From these results, the influence of the units based on 1,4-bis(hydroxydiphenylsilyl)benzene (PS units) on the thermal and physical properties of the copolymers and their films will be discussed.

\section{EXPERIMENTAL}

\section{Materials}

Toluene was distilled over sodium to remove a small amount of water. 1,4-bis(hydroxydiphenylsilyl)benzene (M1) was synthesized according to our previous report. ${ }^{23}$ 1,4-Bis(hydroxydimethylsilyl)benzene (M2) was purchased from Chisso Corp. and purified by recrystallization from a mixture solution of tetrahydrofuran (THF) and $n$-hexane before use. Tris(2,4pentanedionato)chromium (III) was purchased from Dojindo Laboratories. Diiodomethane was purchased from Tokyo Chemical Industry Co., Ltd and used without any purification. Tetramethylguanidine di-2ethylhexanoate was prepared by mixing tetamethylguanidine and 2-ethylhexanoic acid in 1:2 mol ratio for several days to use as a basic catalyst. PolyPS, oligoPS and polyMS's were synthesized also according to our previous report. ${ }^{23}$ PolyMS-1 and polyMS-2 were synthesized in refluxed benzene for $24 \mathrm{~h}$ and $63 \mathrm{~h}$, respectively. Model compound was synthesized from 1,4-bis(chlorodimethylsilyl)benzene and triphenylsilanol in THF in the presence of pyridine.

\section{Copolymerizations}

Poly[(tetraphenyl- $p$-silphenylenesiloxane)-co-(tetramethyl- $p$-silphenylenesiloxane)]s (CP series) were synthesized in refluxed toluene in the presence of the basic catalyst. A typical procedure for $\mathbf{C P - a}$ is as follows.

M1 $(0.42 \mathrm{~g}, 0.88 \mathrm{mmol})$ and $\mathbf{M} 2(0.020 \mathrm{~g}, 0.087$ $\mathrm{mmol}$ ) were refluxed for $24 \mathrm{~h}$ in toluene $(5.0 \mathrm{~mL})$ in the presence of a few drops of tetramethylguanidine di-2-ethylhexanoate as a catalyst using an azeotropic trap to remove water. The reaction mixture after removing the precipitate was poured into an excess amount of methanol to obtain the polymer. Yield: 0.24 g (56\%). ${ }^{1} \mathrm{H}$ NMR $\delta$ (ppm, THF- $\left.d_{8}, 400 \mathrm{MHz}\right): 0.2-$ $0.4\left(12 \mathrm{H}, \mathrm{CH}_{3} \times 4\right), 7.0-7.6(182 \mathrm{H}, \mathrm{Ph}) .{ }^{29} \mathrm{Si} \mathrm{NMR}$ $\delta\left(\mathrm{ppm}, \mathrm{CDCl}_{3}, 79.5 \mathrm{MHz}\right): 0.798\left(-\mathrm{Si}\left(\mathrm{CH}_{3}\right)_{2}-\mathrm{O}-\right.$ $\left.\mathrm{Si}(\mathrm{Ph})_{2}-\right),-1.23\left(-\mathrm{Si}\left(\mathrm{CH}_{3}\right)_{2}-\mathrm{O}-\mathrm{Si}\left(\mathrm{CH}_{3}\right)_{2}-\right),-17.7(-\mathrm{Si}-$ $\mathrm{OH}),-18.7\left(-\underline{\mathrm{Si}}(\mathrm{Ph})_{2}-\mathrm{O}-\mathrm{Si}(\mathrm{Ph})_{2}-\right),-20.5\left(-\underline{\mathrm{Si}}(\mathrm{Ph})_{2}-\mathrm{O}-\right.$ $\left.\mathrm{Si}\left(\mathrm{CH}_{3}\right)_{2}-\right)$. IR, $v\left(\mathrm{~cm}^{-1}, \mathrm{KBr}\right.$ disk): 3069 (m), 3049 (m), 3000 (m), 1590 (w), 1429 (s), 1136 (s), 1117 (s), 1058 (s, br, Si-O-Si), 1027 (s), 1018 (s), 997 (s), 740 (m), 713 (s), 698 (s), 550 (s), 531 (s), 505 (s).

Other copolymers were prepared by the similar method as the preparation of CP-a by changing the ratio of M1 and M2.

\section{Characterizations of Copolymers}

${ }^{1} \mathrm{H}$ NMR and ${ }^{29} \mathrm{Si}$ NMR spectra of the copolymers were measured with Bruker BioSpin AVANCE DRX 400 Spectrometer at $400 \mathrm{MHz}$ and $79.5 \mathrm{MHz}$, respectively. In the case of the ${ }^{29} \mathrm{Si} \mathrm{NMR}$ measurements, the concentration of the polymer in deuterio chloroform solution was $0.1 \mathrm{~g} \mathrm{~mL}^{-1}$, and $0.05 \mathrm{~mol} \mathrm{~L}^{-1}$ of tris $(2,4-$ pentanedionato) chromium(III) was added to the polymer solution as a relaxation agent in order to obtain quantitative ${ }^{29} \mathrm{Si}$ spectra. ${ }^{25} 1,000-37,000$ scans were needed to obtain adequate signal/noise ratios for quantitation. IR spectra were recorded with PerkinElmer PARAGON FT-IR. Gel permeation chromatography (GPC) was carried out to determine the number-average and weight-average molecular weights with Tosoh HLC-802A instrument by using THF as an eluent, equipped with four columns of TSK gels, G5000H $6 \mathrm{H}_{6}, \mathrm{G} 4000 \mathrm{H}_{6}, \mathrm{G} 3000 \mathrm{H}_{6}$ and $\mathrm{G}^{2} 200 \mathrm{H}_{6}$. Standard polystyrenes were used for calibration. X-Ray diffraction (XRD) patterns by the powder method were collected on a RIGAKU RINT 2000 Diffractometer using $\mathrm{CuK} \alpha$ radiation. Samples were annealed for $1 \mathrm{~h}$ at $160^{\circ} \mathrm{C}$ before measurements.

\section{Thermal Analyses}

TGA was performed by using a Shimadzu DTG $60 \mathrm{~A}$ at a heating rate of $10^{\circ} \mathrm{C} \mathrm{min}^{-1}$ with an air flow rate of $50 \mathrm{~mL} \mathrm{~min}^{-1}$ in order to investigate the thermal degradation behavior. DSC was conducted by using a 
SII DSC6200 at a heating rate of $10^{\circ} \mathrm{C} \mathrm{min}^{-1}$ with nitrogen flow rate of $50 \mathrm{~mL} \mathrm{~min}^{-1}$ in order to determine $T_{\mathrm{g}}$ and/or $T_{\mathrm{m}}$.

\section{Preparation of Copolymer Films}

Toluene solutions containing $3 \mathrm{wt}$. \% of the copolymer were cast on polytetrafluoroethylene sheets put at level, and the solvent was evaporated for a few days. The thicknesses of films were in the range of 100$300 \mu \mathrm{m}$. The films were dried in vacuo for $16 \mathrm{~h}$ before measuring each physical property.

\section{Gas Permeability Coefficients Measurements}

Gas permeation measurement was conducted according to the vacuum method using a Tsukuba Rika Seiki, K-315N-01 at $30^{\circ} \mathrm{C}$. A pressure on the permeation side was monitored with a BARATRON ${ }^{\circledR}$ Pressure Transducer. The permeability coefficient, $P$ (Barrer), was calculated from a slope of time-pressure curve at a steady state. The diffusion coefficient, $D$ $\left(\mathrm{cm}^{2} \mathrm{~s}^{-1}\right)$, was calculated from a film thickness, $l$ $(\mathrm{cm})$, and a time lag, $\theta(\mathrm{sec})$, according to the following equation, $D=l^{2} / 6 \theta$. The solubility coefficient, $S$ $\left[\mathrm{cm}^{3}\right.$ (s.t.p.) $\left.\mathrm{cm}^{-3} \mathrm{cmHg}^{-1}\right]$, was also calculated by the equation, $S=P / D$.

\section{Stress-Strain Measurements}

The film samples were cut into rectangular strips of length $50 \mathrm{~mm}$ and width $5 \mathrm{~mm}$. Load-elongation curves obtained on a Shimadzu EZTest. The gauge length was $30 \mathrm{~mm}$ and the crosshead speed was $5 \mathrm{~mm} \mathrm{~min}{ }^{-1}$.

\section{Contact Angle Measurements}

Measurement of static contact angle was performed with KYOWA INTERFACE SCIENCE Co., Ltd, Contact Angle Meter CA-D. Static contact angle was determined by the $4-5 \mu \mathrm{L}$ sessile drop method at $20 \pm 3{ }^{\circ} \mathrm{C}$ using water distilled twice and diiodomethane. Each contact angle value was the mean of ten independent measurements. The film samples were annealed at $160{ }^{\circ} \mathrm{C}$ for $1 \mathrm{~h}$ before measurements.

\section{Film Density Measurements}

The density of each copolymer film was calculated from a precise weight and a precise volume of the product of a film area and a thickness, which was measured with a precision digital micrometer.

\section{RESULTS AND DISCUSSION}

\section{Chemical Structure of Copolymers}

The conditions and the results of the copolycondensation of M1 and M2 are listed in Table I. The molar ratio of M1 to M2 in feed was changed from 9/91 to
Table I. Characterizations of copolymers

\begin{tabular}{|c|c|c|c|c|c|}
\hline \multirow[b]{2}{*}{ Polymer } & \multicolumn{2}{|c|}{ Composition (molar ratio) } & \multirow[b]{2}{*}{$\begin{array}{c}\text { Yield } \\
(\%)\end{array}$} & \multirow[b]{2}{*}{$M_{\mathrm{n}} 10^{-4 \mathrm{~d}}$} & \multirow[b]{2}{*}{$M_{\mathrm{w}} / M_{\mathrm{n}}{ }^{\mathrm{d}}$} \\
\hline & $\begin{array}{l}\text { Feed } \\
x / y\end{array}$ & $\begin{array}{c}\text { Observed }^{b} \\
x / y\end{array}$ & & & \\
\hline oligoPS & $100 / 0$ & $100 / 0$ & $51^{\mathrm{c}}$ & 0.10 & 1.0 \\
\hline $\mathbf{C P}-\mathbf{a}^{\mathrm{a}}$ & $91 / 9$ & $86 / 14$ & $56^{\mathrm{c}}$ & 6.1 & 1.5 \\
\hline $\mathbf{C P}-\mathbf{b}^{\mathrm{a}}$ & $75 / 25$ & $75 / 25$ & 65 & 3.7 & 1.5 \\
\hline CP-c & $50 / 50$ & $45 / 55$ & 60 & 14 & 1.8 \\
\hline CP-d & $25 / 75$ & $24 / 76$ & 85 & 29 & 1.6 \\
\hline CP-e & 9/91 & $8 / 92$ & 81 & 11 & 1.5 \\
\hline polyMS-1 & $0 / 100$ & $0 / 100$ & 80 & 4.5 & 1.5 \\
\hline polyMS-2 & $0 / 100$ & $0 / 100$ & 80 & 21 & 1.7 \\
\hline
\end{tabular}

${ }^{\text {a }}$ These copolymers contained the low molecular weight products. ${ }^{\mathrm{b}}$ Determined by ${ }^{29} \mathrm{Si}$ NMR. ${ }^{\mathrm{c}}$ Soluble parts of polymers. ${ }^{\mathrm{d}} M_{\mathrm{n}}$ and $M_{\mathrm{w}}$ are the number-average molecular weight and weight-average molecular weight, respectively.

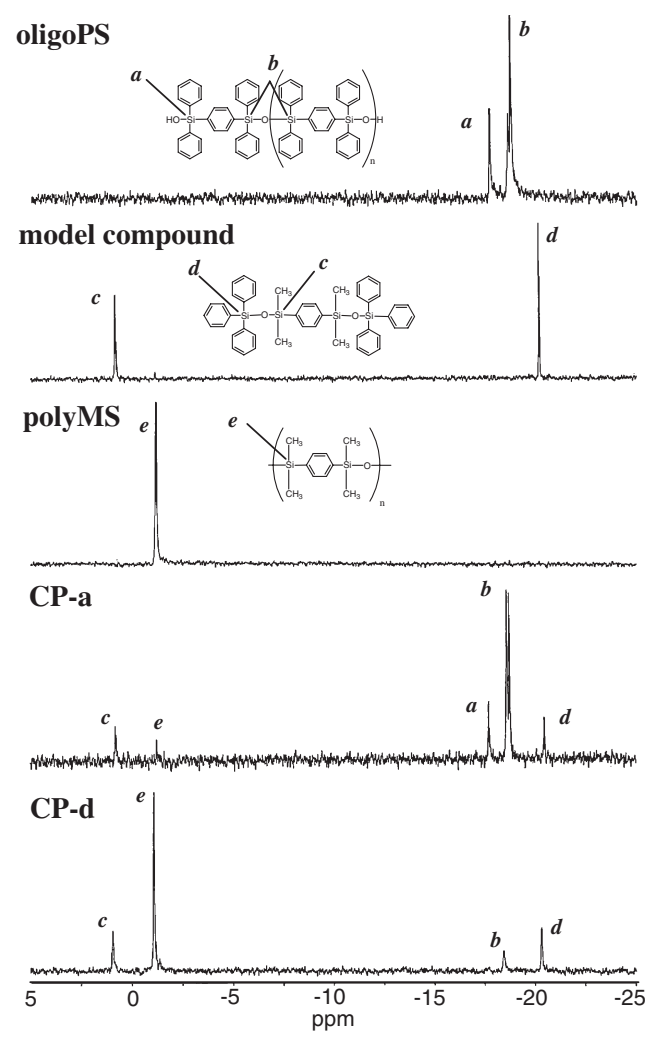

Figure 1. ${ }^{29} \mathrm{Si}$ NMR spectra of copolymers.

91/9. The soluble polymers were obtained in all the compositions except for CP-a. For CP-a, a small amount of precipitate was formed in the reaction mixture. Figure 1 shows the ${ }^{29} \mathrm{Si}$ NMR spectra of the copolymers and the related materials. The quantitative capability of ${ }^{29} \mathrm{Si}$ spectra was confirmed by the accordance of the integrated peak intensities of the peaks $c$ and $d$ in the model compound. In the spectra of CP-c, $\mathbf{d}$ and $\mathbf{e}$ (CP-c and e are not shown), four peaks were observed at $-20,-18,-1.2--1.1$ and $0.8-1.0 \mathrm{ppm}$. These peaks were assigned by the comparison with those of the oligoPS, the model com- 
Table II. Molar ratios of siloxane units

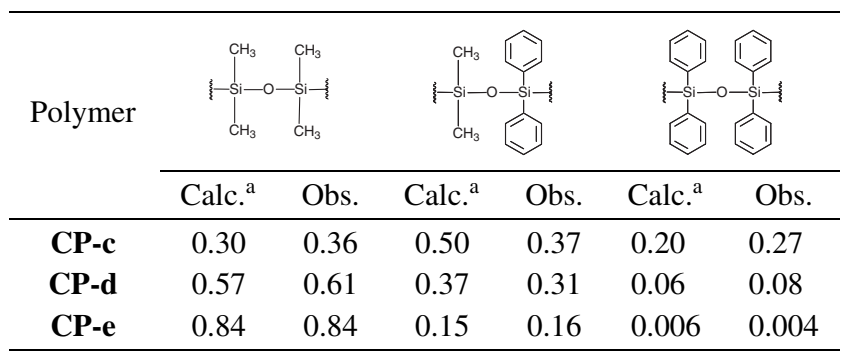

${ }^{\mathrm{a}}$ Molar ratio of the ideal random copolymers.

pound and the polyMS. As a result, the peaks $c$ and $d$ were assigned to the diphenyldimethyldisiloxane units. The peak $b$ and $d$ were assigned to the tetraphenyldisiloxane units and tetramethyldisiloxane units, respectively. In the case of $\mathbf{C P - a}$ and $\mathbf{b}$ (CP-b are not shown), another peak was also observed at $-17.7 \mathrm{ppm}$ which arose from the silanol in the chain end similarly to that of oligoPS. This result showed that the chain ends of these polymers were PS units. However, its peak intensity was larger than the value predicted by their molecular weights. This discrepancy was caused by the low molecular weight products contained in these copolymers, and the split of peak $b$ was also due to these products. On the other hand, peak $a$ was not observed in the spectra of CP-c, d and $\mathbf{e}$. The low molecular weight products were not detected in their GPC charts. Therefore, the chemical structures of $\mathbf{C P - c}, \mathbf{d}$ and $\mathbf{e}$ were investigated in detail. The compositions of these copolymers determined by the ratio of the peak intensities of the diphenylsilyl group (the peaks $b$ and $d$ ) against the dimethylsilyl group (the peaks $c$ and $e$ ) are also shown in Table I. All of the compositions of these copolymers almost coincided with the feed ratios of the monomers. Table II shows the ratios of the three kinds of siloxane units of these copolymers determined by ${ }^{29} \mathrm{Si}$ NMR spectra. Here, the average intensities of the peaks $c$ and $d$ were used for the calculation in the case of the diphenyldimethyldisiloxane units. The observed unit ratios of CP-e almost accorded with those of the calculated values of the ideal random copolymers. However, the ratios of the tetramethyldisiloxane units and the tetraphenyldisiloxane units of CP-c and $\mathbf{d}$ were slightly larger than those of the calculated values. Especially, in the case of CP-c, the difference between the observed value and the calculated value of each siloxane unit was the largest. These results showed that these copolymers had slightly block character rather than the ideal random copolymers. Considering the yield and the molecular weight decreased with the increase of PS units as shown in Table I, the block character would be caused by the lower rate of polymerization of M1 than that of M2.

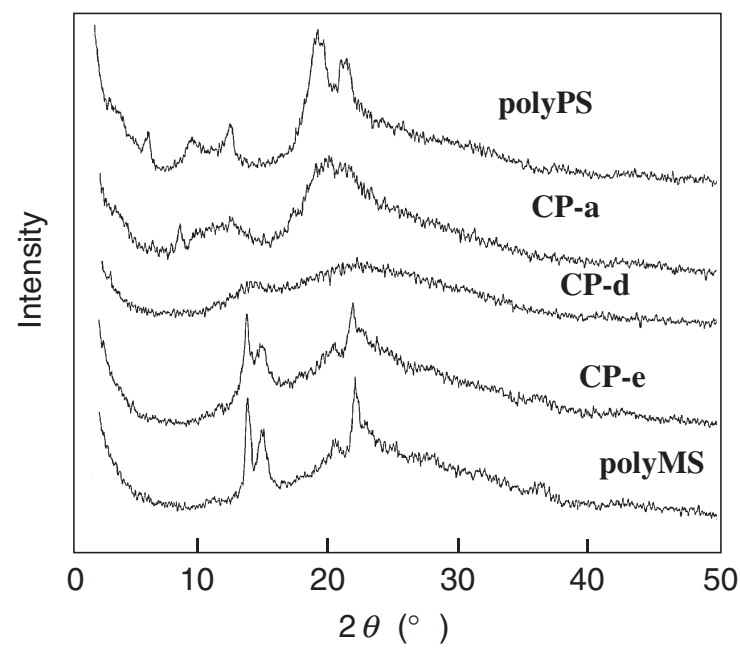

Figure 2. XRD patterns of copolymers.

\section{Physical Structure of Copolymers}

The XRD patterns of $\mathbf{C P}$ series are shown in Figure 2. PolyPS and polyMS were crystalline polymers as reported in the literature. ${ }^{23,26}$ In the chart of $\mathbf{C P}-\mathbf{a}$, the diffraction peaks were observed at $2 \theta=8.6^{\circ}, 12.6^{\circ}, 20^{\circ}$ and $21^{\circ}$, and these peaks coincided with those of polyPS. In the chart of CP-e, the sharp peaks were observed at $2 \theta=14^{\circ}, 15^{\circ}$ and $22^{\circ}$, and these peaks agreed with those of polyMS. Therefore, CP-a and CP-e would contain the crystalline region arising from the PS units and the MS units, respectively. In the charts of $\mathbf{C P}-\mathbf{b}, \mathbf{c}$ and $\mathbf{d}(\mathbf{C P}-\mathbf{b}$ and c are not shown), only two broad halos were observed at $2 \theta=14^{\circ}$ and $21^{\circ}$. From these results, these polymers were amorphous polymers.

\section{Thermal Properties of Copolymers}

$T_{\mathrm{g}}, T_{\mathrm{m}}$ and the enthalpy change $\left(\Delta H_{\mathrm{m}}\right)$ of $\mathbf{C P}$ series are listed in Table III. All the copolymers of $\mathbf{C P}$ series showed $T_{\mathrm{g}}$ 's. The increase of $T_{\mathrm{g}}$ was proportional to PS unit ratio. OligoPS was prepared by pouring the soluble part of the reaction mixture which was obtained during the preparation of polyPS. As reported by our previous paper, ${ }^{23}$ polyPS was a highly crystalline polymer and exhibited no $T_{\mathrm{g}}$ below $400^{\circ} \mathrm{C}$. On the other hand, oligoPS showed the $T_{\mathrm{g}}$ at $126^{\circ} \mathrm{C}$. The different thermal property of oligoPS from that of polyPS would be due to its low molecular weight. The $T_{\mathrm{g}}$ of $127^{\circ} \mathrm{C}$ for $\mathbf{C P}-\mathbf{a}$ was the similar value to that of the oligoPS, which was relatively high among the known polysilarylenesiloxanes., ${ }^{2,6}$ On the other hand, $T_{\mathrm{m}}$ 's of $\mathbf{C P - a}$ and $\mathbf{C P}-\mathbf{e}$ were observed, which supported the results of the XRD measurements. In the case of CP-e, the endothermic peak was observed on only the first heating scan. Considering the sample kept at room temperature for several hours after heating process showed clearly an endothermic peak, $\mathbf{C P}$ - 
Table III. Thermal properties of copolymers

\begin{tabular}{lcccccc}
\hline Polymer & $\begin{array}{c}T_{\mathrm{m}}{ }^{\mathrm{a}} \\
\left({ }^{\circ} \mathrm{C}\right)\end{array}$ & $\begin{array}{c}\Delta H_{\mathrm{m}}{ }^{\mathrm{a}} \\
\left(\mathrm{Jg}^{-1}\right)\end{array}$ & $\begin{array}{c}T_{\mathrm{g}}{ }^{\mathrm{a}} \\
\left({ }^{\circ} \mathrm{C}\right)\end{array}$ & $\begin{array}{c}T_{\mathrm{d} 5}{ }^{\mathrm{c}} \\
\left({ }^{\circ} \mathrm{C}\right)\end{array}$ & $\begin{array}{c}\text { Weight residues } \\
(\%)\end{array}$ \\
\hline polyPS & 323 & -1.59 & - & 539 & 26.3 & 27.3 \\
oligoPS & 313 & -6.39 & 126 & 418 & 26.3 & 22.4 \\
CP-a & 317 & -1.02 & 127 & 464 & 28.4 & 25.1 \\
CP-b & - & - & 96 & 470 & 30.4 & 28.6 \\
CP-c & - & - & 62 & 524 & 37.4 & 34.3 \\
CP-d & - & - & 22 & 513 & 44.6 & 43.2 \\
CP-e & $123^{\mathrm{b}}$ & $-5.42^{\mathrm{b}}$ & -3.8 & 519 & 52.4 & 41.8 \\
polyMS-1 & 136 & -30.2 & - & 411 & 57.4 & 32.4 \\
polyMS-2 & 132 & -23.2 & - & 516 & 57.4 & 35.0 \\
\hline
\end{tabular}

${ }^{\text {a }}$ The melting point, the enthalpy change at $T_{\mathrm{m}}$ and the glass transition temperature determined by DSC on the second heating scan. ${ }^{\mathrm{b}}$ The melting point and the enthalpy change at $T_{\mathrm{m}}$ determined by DSC on the first heating scan. ${ }^{\mathrm{c}}$ The $5 \%$ weight loss temperature estimated from TG curve. ${ }^{\mathrm{d}}$ Weight residues at $700{ }^{\circ} \mathrm{C}$. ${ }^{\text {e }}$ These values were calculated assuming that all of $\mathrm{Si}$ in the polymers were converted to $\mathrm{SiO}_{2}$.

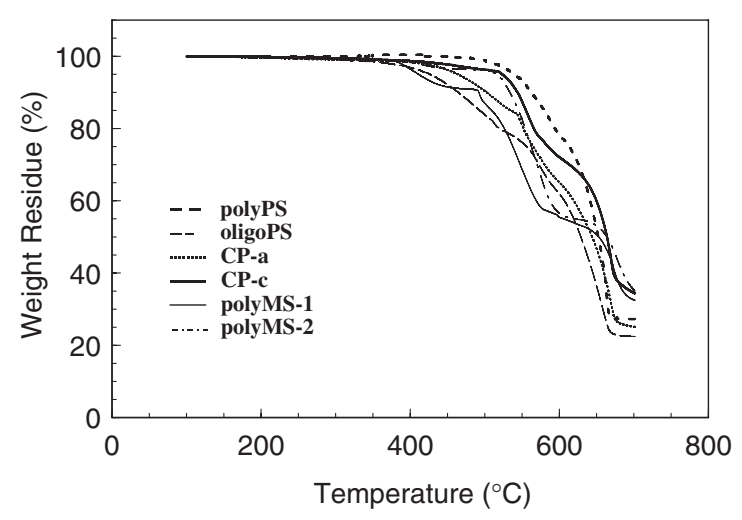

Figure 3. TGA curves of copolymers.

e would be at a supercooling state on the second heating scan.

The TG curves of polyPS, oligoPS, CP-a, CP-c and polyMS's are shown in Figure 3. OligoPS, CPa, CP-b (not shown) and polyMS-1 rapidly decomposed at about $400{ }^{\circ} \mathrm{C}$. The low thermal stability of these polymers would be caused by the thermal decomposition of the silanols in the chain ends because the molecular weights of these polymers were lower than those of other polymers as shown in Table I. From these results, the molecular weight of the polymers played an important role in the thermal degradation temperature. In the TG curve of CP-c, the weight loss of the second step was smaller and the weight residue above $600^{\circ} \mathrm{C}$ was larger than that of polyMS-2. Therefore, the introduction of PS units was effective to improve the thermal stability of the copolymers. The $T_{\mathrm{d} 5}$ 's and the weight residues of the copolymers estimated according to the TGA measurements are listed in Table III. CP-c, which had relatively high molecular weight and high PS unit ratio, showed the highest thermal stability in air, and the $T_{\mathrm{d} 5}$ of this copolymer was $524^{\circ} \mathrm{C}$. It was revealed that the copolycondensation of M1 and M2 were effective to obtain a polysilarylenesiloxane which was soluble in common solvents and showed high thermal stability in air and relatively high $T_{\mathrm{g}}$. Further, the weight residue of CP-d, whose molecular weight was relatively high, coincided with the theoretical value, whereas, those of $\mathbf{C P - a}$ and $\mathbf{b}$ were smaller than the theoretical values. It would be caused by the elimination of the volatile organosilicon compound, such as a triphenyl silanol, from the chain-end as described in our previous report. ${ }^{27}$ It was shown that the molecular weight of the copolymers also affected on the weight residues. On the other hand, the weight residues of CP-e and polyMS's were much smaller than the theoretical values. This difference showed that the amount of the volatile organosilicon compound generated from MS units larger than those from PS units. The same tendency was shown in the literature. ${ }^{16}$

\section{Physical Properties of Copolymer Films}

The films were prepared from the toluene solution of each copolymer by the casting method on the polytetrafluoroethylene sheets. The films of CP-a and b became brittle and fragile, whereas the tough films of CP-c, $\mathbf{d}, \mathbf{e}$ and polyMS could be obtained with their thickness in the range of 100-300 $\mu \mathrm{m}$. The difference of the film forming properties would be mainly caused by the different molecular weights as listed in Table I. Unfortunately, the copolymers, which have the same composition as CP-a and b high molecular weights suitable for the film preparation, could not be obtained by the copolymerizations. As a result, the physical properties of $\mathbf{C P}-\mathbf{c}, \mathbf{d}$, and e films were investigated.

Permeation measurements of hydrogen, oxygen, nitrogen gasses for the CP-c, $\mathbf{d}$, e and polyMS films were conducted at $30^{\circ} \mathrm{C}$. Unfortunately, the measurements for CP-e and polyMS films were not successfully managed because the no negligible pressure changes of a permeate side arising from a gas leak. Then, the evaluation for the polyMS film was referred to our previous paper. ${ }^{24}$ Permeability coefficient, $P$, diffusion coefficient, $D$, and solubility coefficient, $S$, calculated from the obtained pressure curve are summarized in Table IV, together with values for a PDMS and a polystyrene, PSt, referred to the literature. ${ }^{28,29}$ PDMS, which has been well known as a material for an oxygen-enriching membrane, indicates relatively high $S_{\mathrm{O} 2}$ compared with $S_{\mathrm{N} 2}$. CP-c, e and polyMS indicated distinctly low values of permeation parameters against all gasses compared with those of a PDMS, in spite of these contained the same structure 
H. Iто et al.

Table IV. Gas permeation behavior of copolymer films

\begin{tabular}{|c|c|c|c|c|c|c|c|c|c|c|}
\hline \multirow[t]{2}{*}{ Code } & \multirow{2}{*}{$\begin{array}{l}\text { density } \\
\mathrm{g} / \mathrm{cm}^{3}\end{array}$} & $P_{\mathrm{H} 2}$ & $P_{\mathrm{O} 2}$ & $P_{\mathrm{N} 2}$ & $D_{\mathrm{H} 2}$ & $D_{\mathrm{O} 2}$ & $D_{\mathrm{N} 2}$ & $S_{\mathrm{H} 2}$ & $S_{\mathrm{O} 2}$ & $S_{\mathrm{N} 2}$ \\
\hline & & \multicolumn{3}{|c|}{$(\text { Barrer })^{\mathrm{c}}$} & \multicolumn{3}{|c|}{$\left(10^{-7} \mathrm{~cm}^{2} \mathrm{~s}^{-1}\right)$} & \multicolumn{3}{|c|}{$\left(10^{-4} \mathrm{~cm}^{3}\right.$ (s.t.p.) $\left.\mathrm{cm}^{-3} \mathrm{cmHg}^{-1}\right)$} \\
\hline CP-c & 1.0 & 28 & 4.5 & 1.1 & 176 & 4.4 & 2.5 & 1.6 & 10 & 4.4 \\
\hline CP-d & 0.92 & 37 & 6.1 & 1.7 & 585 & 7.6 & 7.6 & 0.63 & 8.0 & 2.2 \\
\hline polyMS & 0.71 & - & $8.8^{\mathrm{d}}$ & $2.8^{\mathrm{d}}$ & - & - & - & - & - & - \\
\hline $\mathbf{P D M S}^{\mathrm{a}}$ & - & 890 & 800 & 400 & 1400 & 340 & 340 & 6.6 & 24 & 12 \\
\hline $\mathbf{P S t}^{\mathrm{b}}$ & $1.0-1.1$ & 23 & 2.6 & 0.79 & 436 & 1.1 & - & 0.53 & 24 & - \\
\hline
\end{tabular}

${ }^{\mathrm{a}} \operatorname{Ref} 28 .{ }^{\mathrm{b}} \operatorname{Ref} 29 .{ }^{\mathrm{c}} 1.0 \times 10^{-10}\left[\mathrm{~cm}^{3}\right.$ (s.t.p.) $\left.\mathrm{cm} \mathrm{cm}^{-2} \mathrm{~s}^{-1} \mathrm{cmHg}^{-1}\right] .{ }^{\mathrm{d}} \operatorname{Ref} 24$.

Table V. Physical properties of copolymer films

\begin{tabular}{|c|c|c|c|c|c|c|}
\hline \multirow[t]{2}{*}{ Polymer } & \multicolumn{2}{|c|}{$\begin{array}{c}\text { Contact angle } \\
\left({ }^{\circ}\right)\end{array}$} & \multirow{2}{*}{$\begin{array}{c}\begin{array}{c}\text { Surface Energy } \\
(\mathrm{mN} / \mathrm{m})\end{array} \\
\gamma^{\mathrm{b}}\end{array}$} & \multirow{2}{*}{$\begin{array}{c}\text { Tensile } \\
\text { strength } \\
(\mathrm{MPa})\end{array}$} & \multirow{2}{*}{$\begin{array}{c}\text { Young's } \\
\text { modulus } \\
(\mathrm{MPa})\end{array}$} & \multirow{2}{*}{$\begin{array}{c}\text { Maximum } \\
\text { strain } \\
(\%)\end{array}$} \\
\hline & $\mathrm{H}_{2} \mathrm{O}$ & DIM $^{\mathrm{a}}$ & & & & \\
\hline CP-c & 103 & 62.2 & 27.4 & 12.5 & 4.5 & 10.8 \\
\hline CP-d & 101 & 68.9 & 22.9 & 7.6 & 2.8 & 27.4 \\
\hline CP-e & 105 & 66.4 & 24.9 & $6.0(0.005)^{\mathrm{c}}$ & $1.3(-)^{\mathrm{c}, \mathrm{d}}$ & $5.1(263)^{\mathrm{c}}$ \\
\hline
\end{tabular}

${ }^{\mathrm{a}}$ Diiodomethane. ${ }^{\mathrm{b}}$ Calculated by the Owens-Wendt equation. ${ }^{\mathrm{c}}$ The data of the film cooled to r.t. after raising to $200^{\circ} \mathrm{C}$ for $5 \mathrm{~min}$. ${ }^{\mathrm{d}}$ Young's modulus was too small to be estimated.

of dimethylsiloxane unit to a PDMS. The gas permeabilities of all gasses through the copolymer films decreased with an increase of PS unit ratio. These results would relate to their chemical structure and the mobility of their polymer chains. The $T_{\mathrm{g}}$ 's of PDMS and polyMS were $-120^{\circ} \mathrm{C}$ and $-20^{\circ} \mathrm{C}$, respectively. ${ }^{2}$ Those of CP-c and $\mathbf{d}$ were higher than these values and increased with the increase of the PS unit ratio as shown in Table III. Therefore, the mobility of their polymer chain was lower than that of PDMS and polyMS. On the other hand, the densities of the films of CP-c, $\mathbf{d}$ and polyMS are also presented in Table IV. The densities increased with an increase of PS unit ratio. These results showed that the copolymer films were denser compared with PDMS or polyMS films. The high densities of these copolymers were attributed to the replacement of the methyl side groups by the phenyl groups. Therefore, these copolymers showed lower gas permeabilities than those of PDMS and polyMS. On the other hand, it was found that the gas permeation behavior of PSt was similar to that of CP-c and d. The density of CP-c was 1.0, and approximately coincided with that of PSt. The PS unit introduced into the structure of polyMS would behave as the same as the side-chain phenyl group of PSt.

The static contact angles on copolymer films against water and diiodomethane and their surface energy calculated by the Owens-Wendt equation ${ }^{30}$ are summarized in Table V. The influence of pendant groups on the surface energy of silicon-containing polymers is not completely understood, however, it has been known that the surface energy is relatively high when the pendant group is bulky group such as a phenyl. ${ }^{31}$ The surface energy of each copolymer was slightly larger than that of a PDMS $(22.8 \mathrm{mN}$ / $\mathrm{m})^{30}$ and the similar values to that of silicon-containing polymers having phenylene moiety such as a dimethylsiloxane-methylphenylsiloxane copolymer $(50: 50 \mathrm{~mol} \%, 24.7 \mathrm{mN} / \mathrm{m}),{ }^{32}$ a poly(phenylmethylsiloxane) $(33.2 \mathrm{mN} / \mathrm{m})^{31}$ and a dimethylsiloxanediphenylsiloxane copolymer $(4.4: 95.6 \mathrm{~mol} \%, 24.0$ $\mathrm{mN} / \mathrm{m}) .{ }^{32}$ Therefore, it was suggested that the surface energy of the copolymers did not change largely by the introduction of PS units and these copolymers had a low surface energy similar to the silicon-containing polymers that were applied to the practical uses.

The mechanical properties of the copolymer films are also shown in Table V. The tensile strength and Young's modulus increased with the increase of PS unit. These characteristics would be attributed to the stiffness of PS unit, which related to the results of the gas permeability and density measurements. The maximum strain of CP-d film was the largest among these copolymers. CP-d was an amorphous polymer and its $T_{\mathrm{g}}$ was $22{ }^{\circ} \mathrm{C}$. It was considered that the mobility of the polymer chain was relatively high. On the contrary, the maximum strain of CP-e film was small which would be due to that CP-e was a crystalline polymer. However, the mechanical property of CP-e film drastically changed after raising $200{ }^{\circ} \mathrm{C}$ for $5 \mathrm{~min}$. The maximum strain of the film was over $250 \%$, and its tensile strength was about $1 / 1,000$ of the film before heating. Considering the results of the DSC measurements, the CP-e film was an amorphous polymer immediately after cooling to the room temperature from the molten state. Therefore, it was shown that the crystalline region of the films exerted much influence on their mechanical properties. 


\section{CONCLUSIONS}

The soluble and high molecular weight copolymers of $M_{\mathrm{n}}$ over $10^{5}$ were obtained when the molar ratio of 1,4-bis(hydroxydiphenylsilyl)benzene in feed was less than $50 \%$. According to the ${ }^{29} \mathrm{Si}$ NMR spectra of the copolymers, these copolymers had the slightly block character.

All the copolymers exhibited $T_{\mathrm{g}}$ 's, those increased with the increase of PS unit ratio. The $T_{\mathrm{g}}$ of CP-a reached to $127^{\circ} \mathrm{C}$ and it was relatively high among the known polysilarylenesiloxanes. From the results of the TGA measurements, the molecular weights of the copolymers played an important role in their thermal decomposition as well as the molar ratios of PS units. The $T_{\mathrm{d} 5}$ of $\mathbf{C P}-\mathbf{c}$ was $524^{\circ} \mathrm{C}$, which was nearly equal to that of the fully aromatic polysilarylenesiloxanes. Tough self-standing films were obtained from the copolymers (CP-c, $\mathbf{d}$ and $\mathbf{e})$ having relatively high molecular weights by the casting method. The gas permeability coefficients decreased and the density of films increased with the increase of the molar ratio of PS units. In addition, the tensile strength of the copolymers increased and the surface energy of the copolymers did not increase largely by the introduction of PS units. Consequently, it was revealed that the copolycondensation of a bis(hydroxydiphenylsilyl)arylene with a bis(hydroxydimethylsilyl)arylene was effective to obtain a polysilarylenesiloxane having relatively high $T_{\mathrm{g}}$, high $T_{\mathrm{d}}$ in air, and the dense and tough films could be prepared from these copolymers owing to their good solubility.

Acknowledgment. We sincerely appreciated to Associate Professor, Dr. Nobukatsu Nemoto, Faculty of Engineering, Nihon University, for very useful discussion with him.

\section{REFERENCES}

1. R. L. Merker and M. J. Scott, J. Polym. Sci., A, 2, 15 (1964).

2. P. R. Dvornic and R. W. Lenz, "High Temperature Siloxane Elastomers," Hüthing \& Wepf, Basel, 1990, Chapter III.

3. N. Okui, H. M. Li, and J. H. Magill, Polymer, 19, 411 (1978).

4. M. Ikeda, T. Nakamura, Y. Nagase, K. Ikeda, and Y. Sekine, J. Polym. Sci., Polym. Chem. Ed., 19, 2595 (1981).

5. R. L. Merker, M. J. Scott, and G. G. Haberland, J. Polym.
Sci., A, 2, 31 (1964).

6. W. R. Dunnavant, Inorg. Macromol. Rev., 1, 165 (1971).

7. J. M. Funt, R. D. Parekh, J. H. Magill, and Y. T. Shah, J. Polym. Sci., Polym. Chem. Ed., 13, 2181 (1975).

8. C. U. Pittman. Jr, W. J. Patterson, and S. P. Mcmanus, J. Polym. Sci., Polym. Chem. Ed., 14, 1715 (1976).

9. P. R. Dvornic and R. W. Lenz, J. Polym. Sci., Polym. Chem. Ed., 20, 951 (1982).

10. Y. Nagase, T. Masubuchi, K. Ikeda, and Y. Sekine, Polymer, 22, 1607 (1981).

11. Y. Nagase, K. Ikeda, and Y. Sekine, Polymer, 23, 1646 (1982).

12. Y. Nagase, T. Nakamura, A. Misawa, K. Ikeda, and Y. Sekine, Polymer, 24, 457 (1983).

13. Y. Nagase, T. Fukatsu, K. Ikeda, and Y. Sekine, Polymer, 24, 463 (1983).

14. L. W. Breed, R. L. Elliott, and M. E. Whitehead, J. Polym. Sci., A-1, 5, 2745 (1967).

15. R. E. Burks Jr, E. R. Covington, M. V. Jackson, and J. E. Curry, J. Polym. Sci., Polym. Chem. Ed., 11, 319 (1973).

16. P. R. Dvornic and R. W. Lenz, Polymer, 24, 763 (1983).

17. H. D. Zhu, S. W. Kantor, and W. J. MacKnight, Macromolecules, 31, 850 (1998).

18. P. R. Dvornic, H. J. Perpall, P. C. Uden, and R. W. Lenz, J. Polym. Sci., Polym. Chem. Ed., 27, 3503 (1989).

19. P. R. Dvornic and R. W. Lenz, Macromolecules, 25, 3769 (1992).

20. Y. Kawakami, Y. Li, Y. Liu, M. Seino, C. Pakjamsai, M. Oishi, Y. H. Cho, and I. Imae, Macromol. Res., 12, 156 (2004).

21. Y. Li and Y. Kawakami, Macromolecules, 32, 3540 (1999).

22. J. Y. Moon, T. Miura, I. Imae, D. W. Park, and Y. Kawakami, Silicon Chem., 2, 139 (2002).

23. H. Ito, E. Akiyama, Y. Nagase, A. Yamamoto, and S. Fukui, Polym. J., 38, 109 (2006).

24. Y. Nagase, J. Ochiai, K. Matsui, and M. Uchikura, Polymer, 29, 740 (1988).

25. G. N. Babu and R. A. Newmark, Macromolecules, 24, 4503 (1991).

26. N. Okui and J. H. Magill, Polymer, 18, 1152 (1977).

27. H. Ito, E. Akiyama, Y. Nagase, A. Yamamoto, and S. Fukui, Polym. J., 38, 1068 (2006).

28. T. C. Merkel, V. I. Bondar, K. Nagai, B. D. Freeman, and I. Pinnau, J. Polym. Sci., Part B: Polym. Phys., 38, 415 (2000).

29. J. Brandrup and E. H. Immergut, "POLYMER HANDBOOK," John Wily \& Sons, New York, 1975, p III 236.

30. D. K. Owens and R. C. Wendt, J. Appl. Polym. Sci., 13, 1741 (1969).

31. D. V. Patwardhan, H. Zimmer, and J. E. Mark, J. Inorg. Organomet. Polym. Mater., 7, 93 (1997).

32. J. I. Kroschwitz, "Concise Encyclopedia of Polymer Science and Engineering," John Wiley \& Sons, New York, 1995, p 1055. 